\title{
Added value of information and information systems: A conceptual approach
}

\author{
Rahmatollah Fattahi, Ph.D. ${ }^{1}$ \\ Ebrahim Afshar, Ph.D. ${ }^{2}$
}

\begin{abstract}
Purpose - Information, due to its nature, has numerous capabilities. Through utilizing these capabilities, information systems can add to the value of information. The purpose of this paper is to explain where and how added value emerge form the work processes in library and information professions.

Design/methodology/approach - The paper begins with a review of the related literature and then takes a conceptual approach to discuss different values of information and IR systems; elaborates on how each of the processes like assessment of needs, selection, description/organization, storage/processing, search/retrieval, and dissemination generate capabilities that lead to added value.

Findings - The paper identifies that added value is generated through processes such as reproduction, exchange, transfer, refinement, analysis, interpretation, synthesis, and regeneration of information. Many of such processes turn information into knowledge.

Practical implications - Librarians and information specialists need to find practical ways in their work processes regarding how to design information systems and services which can generate added value for information.

Research limitations/implications - This paper is based on the author's reflections on the matter of added value generated by library and information practice. Further empirical studies are needed to substantiate the extent to which such values are generated through information systems and services in the real world.

Originality/value - In the present evolving conditions, library and information professionals are able to add to the value of information by sharing their knowledge with the expertise of computer scientists and finding ways and up-to-date methods of optimizing existing systems, as well as designing new systems. These are the two strategies along which the profession should guide its educational, research and practical endeavors.
\end{abstract}

Keywords: Information, Information systems, Information services, Added value.

Article Type: Conceptual paper

\footnotetext{
1 Associate Professor, Department of Library and Information Science, Ferdowsi University of Mashhad, Iran (fattahi@ferdowsi.um.ac.ir)

2 Assistant Professor, Department of Library and Information Science, Isfahan University, Iran (e_afshar@hotmail.com)
} 


\section{Introduction}

Library and information services as two professions with information and knowledge as their subject of interest, besides serving community's need involve generate added value in the strict financial terms. That is the added value generated from the processes and functions undertaken by them. The main functions of the two include needs assessment, selection, provision, processing, organization and dissemination of information. The subject matter of these functions is information - the engine for the progress of individuals, communities, and nations.

A considerable body of literature has been published on information and its value to the scientific, industrial, economic, social, political value of information. Cleveland (1982, 1985), Burk and Horton (1988), Maguire (1990), Matarazzo and Prusak (1995), Volpe National Transportation Systems Center, (1998), and Woldring (2001) have enriched our thoughts about the value of information to the contemporary organization particularly where library managers are under pressure to demonstrate their worth and the value of their library. Robert Hayes (1997) in his contribution to the International Encyclopedia of Information and Library Science has comprehensively examined the value of information from micro and macro economic points of view. An overview of the library literature and the literature of other fields indicates that nowadays not only library and information service professionals, but also many other professions highly value information. Today the motto 'information is power' has become a commonplace truth. Nevertheless, it appears that members of the community, and even library and information managers do not have a clear understanding of what constitutes added value in respect to information (Matarazzo and Prusak, 1990) The same is true about many top managers who rarely use the library directly and thus have an unclear understanding of its value (Saracevic and Kantor, 1997)

The aim of the present paper is to explain where and how added value emerge form the work of library and information professionals. But, it seems in order first ask ourselves what added value is?

What is added value?

The Oxford English Dictionary quotes the definition provided in the Terminology of management and financial accounting (1974) for added value as "the increase in market value resulting from an alteration in the form, location, or availability of a product or service, excluding the cost of bought-out materials or services". Another definition, also quoted in the OED, maintains added value to be "the gap between what the customer pays and what the manufacturer and supplier has to pay for the material". In the profit making sector, all the effort is directed towards either generating added value or boosting it, that is maximizing the gap between the value of the input and output.

The problem is how added value could be calculated, or even considered in the strict terms, for the products of library and information services as long as they are not selling their products, or even if they sell them, they are not looking for profit (i.e. just to cover expenses partially or entirely)? Obviously, the answer to this question for those sections of library and information services which are run for profit making is a task in the hands of accountants.

\section{Added value in information systems and services}

The value of information can be addressed from different perspectives. Top managers see the 
value in decision making and operational management (Marshall, 1993; Hayes, 1997). Some researchers emphasize the monetary value of information and argue that the cost of a professional user's time and effort to obtain information elsewhere far exceeds the cost of providing a library or an information system (Griffiths and King, 1993; Keyes, 1995). The value of information in time saved, productivity and improved work quality is highlighted in a research carried out by Volpe National Transportation Systems Center (1998). Similarly, Koenig (1992) stresses the correlation between the costs of information services and corporate productivity. To McGee and Prusak (1993), the value of information lies in its use for competitive corporate strategy. The ability to acquire, manipulate, interpret, and use information makes it possible for organizations not only to survive but also to be ahead of their rivals.

Reports on the added value of information released in some countries or economic sectors indicate the strategic attention paid to this matter. For example, the Georgia Technical Institute installed a campus-wide online library system in 1986 and reduced the costs of its literature searches by $\$ 1.2$ million a year. Another case study was the library at the Houston division of Texas Instruments. In a survey conducted by the library, users' responses indicated that the library saved the company $\$ 268,800$ a year and increased users' job proficiency by a value of $\$ 523,000$ a year. From an annual investment in the library of $\$ 186,000$ a year, Texas Instruments netted $\$ 959,000$ in benefits--a 515 percent rate of return. (quoted in Matarazzo, et al., 1987). From an Asian perspective, the added value of the information market has gained much attention. The Government of Shanghai's official website (2004) states that the information industry in that state generated 35.04 million Yuan in the year 2000. That figure shows a $28.8 \%$ growth compared to the previous year. The added value gained from the production of information was 1.25 billion Yuan, and that figure for information services has been 12.09 billion -a 13\% growth compared to the previous year.

Information in electronic form is capable of generating even more value. Bothma (1996) points to some properties of electronic information among the most important factors for its added value. For example, at present, by synthesizing text, voice, and images an increasing number of multimedia resources are generated; hundreds of thousand of job opportunities are created, even in developing countries. This has created a considerable added value.

Overall, one could conclude that added value depends on factors such as the quality of the product itself, the method and quality of innovation, the type of utilization, conditions of use, the individual user (or the customer), the time of use, and even the place of investment and use. Such factors, as will be discussed later in this paper, are applicable to information and information systems. Also, the notion of added value in relation to information services is not limited to economics. Such services spread knowledge in the society. To elaborate this, we first carry out an analysis of the capabilities and values of information. Then we elaborate on the capabilities of information systems for generating added value.

\section{A. Capabilities and values of information}

Information due to its very nature is capable of generating added value. In this section, we will elaborate on the characteristics that make this possible. The next section of the present paper will discuss capabilities of information retrieval systems for the same thing. 


\section{Information can be purchased and sold.}

Many purchasable commodities are capable of generating added value as well. That is, they could be purchased first, and then sold for a higher price. Information is not an exception to this rule. The producer of information may sell it many times over. The buyer in turn may also sell that information in certain conditions. Robert Hayes (1997: 119) considers this attribute as "capital resource". He stresses that information could be sold or given away without loosing the value and the content.

The more a piece of information is capable of being bought and sold, the more its value may be increased. No doubt, because of the increasing educational, research, industrial, and economic activities on a global scale, the trend of production (provision) and consumption (demand) is surging. The increasing number of publishers, information suppliers and Internet service providers (ISPs) and the overwhelming production of a variety of electronic information resources and databases is an indication of demand. This shows the capability of information as a commodity.

\section{Information can be used and reused repeatedly}

One distinctive attribute of information is that it can be used repeatedly. In other words, unlike many other assets, information is reusable. For example, some information an individual or a company generates or buys for some purpose, could be used for other purposes, even by other individuals and companies. Think of the photocopy made of a journal article through a document delivery system. Another example is when others who borrow through inter-library loan use the resources of a library, which have been acquired to meet the needs of that library's target users. This is an indication of the fact that information potentially has added value, i.e. it is capable of returning much more than that which has been paid to obtain it. Hayes (1997: 120) maintains that the cost of information is independent of the measure of utilization. That means that the degree of utilization is not proportionate to the investment.

\section{Information can be shared}

Some commodities are capable of being used simultaneously by multiple users. Information is one such commodity that enjoys this capability at the highest level. It is able to be used in high amounts without any depreciation caused by multiple uses. For example, many users might use a certain book. In the same way, tens of users or several libraries could use an electronic source or a database at the same time. Overall, "resource sharing" has allowed optimization of information resources over the last two decades. Resource sharing has proven its economic value. Computer technology and networks have greatly facilitated this sharing.

\section{Information can be transferred through time and space}

Information, when recorded on 'hard material' (i.e., paper, metal, plastic, etc.) is similar to other commodities with regard to transportation. Books and journals, audio-visual materials are transported like other materials: it takes equal amount of time and energy and money to convey them through time and space. Despite all the measures taken, transportation of material goods involves time delays, disruption, loss, etc. However, since transmission of electrons has become the vehicle for conveying information from one point to the other, the time and energy factors have become almost non-existent and the cost has decreased relatively, even since telegraph was invented. In our time, electronic information can be 
transferred easily with minimum cost. It may be dispatched to far distances via telecommunication channels to consumers. Distribution of e-books, e-periodicals, e-files, erecords and so on regional, national, and global scales is a common practice nowadays. The ease of transfer of information in a networked world (i.e., Internet) is the very core of the concept of an information society, expected to intrigue unprecedented cultural and political changes around the world. Also, information can be accessed and 'consumed' when the user is willing to. This attribute is much valued by consumers of information: consumers need not be present at a specific time and place in order to be able to use it.

\section{Information can be processed}

Similar to any raw material, information is capable of being processed according to a certain plan or program and under certain conditions to generate new information. The new information could be used for new and higher purposes. An important point in this respect is that, compared to other raw materials, processing of information in many cases is simpler and less costly. In other words, investment for developing information processing systems (such as library softwares) requires fewer resources, yet its output in the long run is more. As will be discussed later, information in electronic format is capable of being processed further; hence it generates a higher degree of added value.

\section{Information can be reproduced}

Some commodities have the capability of being produced in large quantities after the initial investment. Also, it is possible to reproduce such commodities later on with minimum expenses. This attribute increases the added value. Information resources enjoy such capability. They can be reproduced in multiple copies once generated for the first time through writing, compiling, translating, etc.

Similarly, reprints or new editions may be produced and sold in large quantities. Offset makes multiple uses of the technology with which earlier editions were prepared. Card catalogs could be reproduced; databases could be set up using bibliographic records through copying. Another prominent example is the legal copying of full text electronic resources from the Internet.

\section{Information can be refined}

One interesting characteristic of information that increases its added value is the fact that it is refinable. Normally, with the increase in size of information over time, and increasing difficulty in retrieval, attempts to refine information (i.e. to identify and maintain useful information and delete of useless portions) become necessary. This, in fact, adds to the level of control over existing information and increases access to it, as well as facilitates retrieval and saves time. All of these factors, especially time saving, involve added value. Weeding in libraries is performed for the same reason (i.e. to refine information). Preparing a new edition of an information resource and at the same time, putting aside the older edition, is in fact an act of refinement. This is also true with regard to databases: with each edition, the information content of records is further improved, and with the deletion of unnecessary records one adds to the usefulness of the database. Another possible example is that, by narrowing their search results, users of information systems can refine the information they retrieve. 


\section{Information can be interpreted, inferred, and adapted}

Information is a commodity that may be used in a variety of ways. Different understanding of a piece of information, in other words, different interpretations of that information is always possible. Throughout history, this property has been the reason for many intellectual, cultural, and political developments. This property, i.e., motivating consumers to react and provide their interpretations in the form of new interpretations or adaptations and creation of new works, is probably a prime example of how added value is added to information.

\section{Information can be synthesized and converted into knowledge.}

The capability of information for synthesis is huge. On the most basic level, the survival of many living creatures, particularly human beings, and their compatibility with the changing environment, is dependent on such capability. In the case of human beings, the capacity of information for analysis and synthesis leads to the generation of new information (in particular in recorded forms). Books, articles, documents and records and so on, are products of compilation, analysis, and synthesis of information. Production of new knowledge is, in fact, the transcendental stage of such processes.

Compared to information, knowledge enjoys a higher level of added value. It can be more effectively utilized in strategic decision-making. Because of the same reason, in some societies, instead of generating and improving access to information, the emphasis has turned toward exploring ways of transforming information into knowledge. When conditions are ready, information in synthesis with existing knowledge (approaches and epistemological frameworks) is capable of turning into knowledge. Robert Hayes (1997: 120) considers information a public good and knowledge a private good. He believes that information may be synthesized with other information, that it transforms it and shapes new theories, and eventually generates new knowledge. This is the most valuable capability of information, vital to the prosperity of society. Information is the essential constituent for the generation of knowledge. The content of an authoritative encyclopedia, such as Encyclopedia Britannica, represents the accumulated knowledge of human beings, and is based on the synthesis of information created over many centuries, and in fact is new knowledge.

\section{B. How do information systems generate added value?}

After discussing the nature of information and its capacity for generating added value, we now see how such added value actually is created. Information added value does not happen by itself. Certain processes should take place in order for this to take place. Since to achieve this is impossible or extremely difficult for individuals, it is reasonable to assign this social responsibility to one or a number of professions with required knowledge and skills. The library profession from early days (by whatever name it was then known) has had the responsibility for the processes and functions that create added value out of information (i.e. selection, acquisition, processing organization, and dissemination of information). The profession gradually and over a long time defined and implemented such process within the framework of information systems. Essentially, the library itself is an information system that performs the variety of functions mentioned above within the framework of an integrated process, with the purpose of providing society with easy and quick access to information. In this way, libraries and information centers take action to create different systems ranging from very simple ones (such as making lists and catalogs of resources, i.e., manual systems) to advanced forms (i.e. intelligent and networked computer systems). 
Easy and quick access to desired information is two major parameters in designing information systems. This is to save users' time, in particular experts' time. The outcome of such time saving is generation of added value. In this sense, the library and information center, and even the Internet are information systems. In most cases, of course, by information system we mean one of more bases of certain structures with the goal of storage and retrieval of information. For example, a library OPAC, a database of journal articles, a dissertation abstract and the like, and also library websites are major and applied parts of the information system.

Over the last several decades, librarians have gradually succeeded in increasing the capabilities of information systems in order to change their capacity, speed, and accuracy of information storage and retrieval. They have attempted make it possible to maximize the benefit (or add value) taken out of every piece of information. A number of capabilities that add to the value of information could only be achieved through using information systems, in particular computerized and electronic. Examples are simultaneous use of information, electronic exchange of information, copying and reproduction of bibliographic information, transforming the format of storage and so on. Hayes (1997: p.124) states that information technology has exponentially increased the value of information.

In this section, we will provide an analysis of the processes and functions of libraries and information service centers to show how they add to the value of information. What is taken place in creating an information system is a process involving a number of specific operations that librarians and information experts do routinely. Most of these operations, that are performed using bibliographic information, generate added value. Taylor (1986) considers that three processes lead to the generation of added value with regard to information. These are "organizing", "analyzing", and "judgmental" processes. Within each of these three major processes there are additional specific activities but the library and information professions consider these three as their main functions. "Organization" is performed through operations such as descriptive and subject cataloging, classification, and indexing. "Analysis" is part of needs assessment, organization, and information seeking behavior. "Judgment" is an integral component of the selection or collection development policy (of resources based on agreed standards). Judgment is also taken into consideration in information retrieval (evaluating and ranking the results on the basis of their relevance) and is a part of the performance assessment of the library. Similarly, the three main functions of the library profession (i.e., selection and acquisition, organization, and dissemination of information) are processes that make it possible to add more value to information and to provide a framework for transforming information into knowledge.

Processes performed in information systems and the resulting capabilities that add to the value of information are:

\section{Selection and acquisition of information resources}

Selecting useful information resources that best meet the needs of users is one of the first and most important requirements of an information system. If this is done properly, users of the system will have access to useful and relevant information, which can be critically important for them. Therefore, resources rightly selected for an information system will be followed by more and better use, in addition to saving the time that users spend to access that information. This is one source of added value. 


\section{Description and organization of information resources}

Compared with the function of selection, the description and organization of information add more to the usefulness of information stored in the system. In other words, most of the capabilities that add value to information are created at the stage of organization. Even capabilities, which surface at the stage of search and dissemination, are dependent on the quality of description and organization.

An ideal approach to description and organization of information, capable of creating utmost added value, is the one that requires each information resource to be catalogued and organized prior to its publication ( $\mathrm{CIP}=$ Cataloging in Publication). Other libraries and information centers can use the bibliographic record created for that item instead of repeatedly recreating it. In this way, a huge saving of time and effort takes place and organization of material is done at minimum cost.

Recent advances in the production of electronic resources and their description at the very stage of creation of files, based on metadata format, has doubled the added value of information. Resources based on metadata format can be readily and automatically described and organized. Internet search engines identify and index metadata resources more easily in increasingly effective ways.

Organization and representation (i.e. subject analysis, indexing and classification) of knowledge, carried out to create cohesion and order, are among the most important capabilities of an information system. They also add to the value of data. In other words, organization and representation of information based on thesauri and classification schemes make quick and easy retrieval and location of information possible. In addition, organization of knowledge improves the user's understanding of the structure of knowledge and of interrelationships among different disciplines.

Among the existing ways and approaches to organize knowledge some are more capable of adding to the value of information. Bothma (1996) observes that providing access to information via hierarchical structuring and hyperlinks is one of the most distinct ways of adding to the value of information. Similarly, Fattahi and Parirokh (2002) have considered the multi-level and hierarchical structure in the description and organization of information a most desirable approach for translating information into knowledge. Through a prearrangement of categories and sub-categories of bibliographic families (i.e., works and their various editions and manifestations) and the links between information entities at a higher or lower level, the systematic multi-level structure called "Super record" makes the organization and representation of information sources more comprehensible to the user.

In a more general term, a library collection is an act of generating added value. By carefully selecting a small portion of the universe of information and forming a collection, librarians in fact create a 'Super Text'. Such a 'super text' has the function of shortening the time and effort that otherwise potential users need to spend in order to gain access to information they need. In fact, it might be correct to say that assigning Collection Level Descriptor (LCD) to segments of a collection is an example of how the concept of 'super text' comes into play. By assigning level descriptors to a collection the user is provided with a structured, open, standardized, and machine-readable metadata that gives them an understanding of what is in the collection beyond individual items. Macgregor (2003) has discussed the application of LCD for digital libraries for both user resource discovery and institutional collection management. 


\section{Storage and processing of information}

Storage of bibliographic data in information systems, in particular in a standard format (such as MARC format and/or Dublin Core Metadata), creates a variety of capabilities. These capabilities add to the value of information considerably. In fact, by de-construction of bibliographic information and storing such data in different fields and sub-fields information systems provide the potential upon which a number of new functions become possible:

\section{a. Capability of copying, exchange, and transfer of information}

Perhaps one of the most important capabilities that add to the value of information in computerized systems, particularly in bibliographic databases, is the possibility of copying and transferring records from one system to another. Bibliographic records have a considerable market value. For this reason, some cataloging institutions and bibliographic agencies have invested heavily in creating huge bibliographic databases to provide customers with ability to copy and transfer records in information systems. For example, OCLC as a bibliographic agency pays a certain amount to obtain each bibliographic record from a member library. Based on a cost-benefit analysis, each MARC record in OCLC databases (e.g., World Cat, Authority file, interlibrary loan system) worth around \$27 (Mathews, 2000). In fact, such agencies invest once to create a record, then sell it unlimited times. In this way, not only do they recoup what has been invested for the purchase of the record, but also add to the value of their database. Over a period of ten years (1988 until 1998) OCLC earned more that $\$ 486$ m (OCLC Annual report, 1998). Similarly, in many countries a number of institutions, including national libraries, have been able to add a good deal of value to their bibliographic databases. Many libraries now use national bibliographies either online or on-disk for a minimum cost and catalog their collection by transferring relevant records to their own library systems.

In addition to cataloging agencies and national bibliographic agencies, copying and transferring of information (records) is available in many ordinary databases. Libraries, and even individuals can buy records they need with minimum cost and add them to their own databases. This has become a routine practice over the last decade in many countries. Libraries save a lot of time and money in this way, while consistency in data exchange and storage, which is an important factor in easy access is achieved.

In the web environment, too, a similar possibility for copying and transfer of bibliographic data has greatly added to the value of information. Users, including librarians, are now able to make copies of what they have retrieved on the web for free. They can forward it to others via email services. At present, search in the catalog of large libraries, particularly national libraries, has become a routine. Catalogers easily transfer the desired records from the database of, for example, the Library of Congress to their own database albeit taking copyright issues into consideration.

\section{b. Capability of further processing of information}

In addition to the copying and reproducing of information made as a result of storage, further processing is another possibility that adds to the value of information. As mentioned previously, each record is consisted of different fields and subfields. It is possible to consider certain tasks for the bibliographic record according to the needs of the library. By tagging indexable and searchable fields (like the fields for authors, titles, subjects, and call 
numbers), and by defining data elements that help the user to carry out advanced searches, or by arranging and sorting the results (i.e., the output) in the desired formats (e.g. authors, subjects, publication dates, language, type of material, etc.) the same data in a single database are used in different ways to make the search and retrieval quicker and easier and more comprehensible, and thus push the added value further.

Other possibilities of further processing of data stored in bibliographic databases include flexibility of output and display of information, housekeeping and report generation for different purposes and information management, which will be discussed later in this paper.

\section{c. Possibility of global change in the database}

One important advantage of computerized systems in terms of processing is the possibility of performing global changes/modifications/corrections to certain data elements in all the records stored in the database. For example, it is possible to modify or replace a personal or corporate name heading, or a subject heading with another one in all the records within the database in order to change the existing one we consider no longer appropriate or correct. This means a huge saving of time and effort in data entry, impossible otherwise. The consistency achieved in data entry greatly enhances the accuracy of search and retrieval. Altogether, as the possibility of global change increases, it makes better and easier processing of bibliographic data possible.

\section{Integration of information}

One very clear advantage of electronic information systems is the capability to link/integrate components of the system to one another, using linking techniques and standards of data exchange. This concept is called integration. The purpose of maintaining integration is easy access to separate modules as well as to exchange and sharing of data. For example, in a computerized library system all modules (such as acquisitions, cataloging, and loans) are linked making it possible to share and/or exchange information across different files in the system. In such a situation, the librarian can use the same terminal to access information stored in other sections, search in them, and transfer data, as well as carrying out quality control (i.e., editing records). The value of such capability in terms of time and money saving (no need to retype or re-enter data already existing in one section to another section), simplicity of work (no need to exit from one module in order to enter another), consistency of data, and control is immense.

Integration in an information system for end users entails added value. The end users are able to lodge their request in one spot (=one stop shopping). An advantage of this can be seen when using integrated library systems. In such environment, end users easily visit different sections of the system and access information they need, reserve books, check their borrowing records, etc, without the need to change the user interface. The same is true with regard to websites and Web-based library systems. The hyperlink technology available in the web environment is also a dramatic development for integrating information regardless of type and location.

As mentioned before, data sharing and information sharing among multiple systems (libraries and information centers) made possible by computer and networking technology, is one basis for the increase of information added value In other words, the possibility of sharing requires information systems, in particular those that are computerized and 
networked. Over the last two decades, information systems at the local, national, and international level have been developed in which data sharing has been an important activity.

Added value as a result of information sharing takes place when a specific investment, like the purchase of a database, an electronic journal or book, is made; then what is purchased is downloaded into a system and made available to tens or even hundreds of end users. In fact, the amount of initial investment is broken down among tens of libraries or institutions. In another dimension, the Internet, and in particular, the WWW as a global information system, have made the concept of information sharing tangible by making it possible to have global access to millions of sites for end users.

\section{Information search and retrieval}

The variety of capabilities that have enhanced the performance of information systems also enables such systems to easily retrieve information otherwise impossible or difficult and time consuming by mechanical systems. Such capabilities are invaluable to librarians, information workers and end users, in terms of accuracy as well as speed. For example, with regard to acquisitions and cataloging, librarians by using advanced and accurate search techniques, even based on one single component, retrieve their desired records; and avoid creating new records (i.e., doing original cataloging) which is expensive and time consuming.

Examples of such advanced capabilities could be seen in networked system of OCLC, where thousands of catalogers and acquisitions staff, and even end users visit OCLC database every day from all around the world. The fact that end users are now using OCLC is one aspect of the added value of bibliographic information stored in OCLC databases.

\section{a. Advanced search/retrieval capabilities}

Advanced search capabilities have advantages such as accuracy and exactness in retrieval and identification of relevant information for end users as well. This prevents repeated searches and makes considerable savings in time and energy. The value of advanced searching is more obvious when searching millions of web pages through a variety of advanced search options.

Some of the advanced search capabilities which are used more frequently in many information systems include combined search (using AND, OR, NOT, AND NOT operators), limiting search (based on, for example, language, place, date, type of material, publisher, type of the site), concept search for avoiding false drops, search by using controlled vocabulary authority files (subject headings or thesaurus descriptors) in the form of relational files, and so on.

\section{b. Using relational files to expand or limit a search}

As mentioned before, information systems increase accuracy in retrieval by utilizing relational files (such as subject heading files, thesauri, or authority files). This is of high value to users. In addition, the ability to search in relational files, in particular subject headings and thesaurus files enables users to review these files and develop a relative understanding of the relevance of subject terms prior to searching. Hierarchical relationships, such as broader, narrower and/or related terms, and preferred and nonpreferred vocabulary (i.e., 'see' references) articulated in such files guarantees the 
effectiveness of searches in the database. Displaying relationships between/among different subject areas makes understanding of the structure of knowledge easier.

\section{c. Facilities for hypertext searching in electronic resources}

In addition to the capabilities mentioned above, hierarchical, and in particular, hypertext search facilities in databases and electronic resources lead to much quicker searching and more relevant results, adding to the value of information stored in such resources considerably (Bothma, 1996). Nowadays, many users of electronic databases and websites apply such searches to trace information they need. In some library catalogs hypertext links include major elements in bibliographic records, such as the main entry, added entries, subject headings and in particular, in thesaurus structure with links to the database, hypertext technology is used to limit or expand searches. Examples of these hypertext links in web-based catalogs and other bibliographic databases are numerous.

Another context in which the use of hyperlinks can add to the value of bibliographic information in OPACs is to relate and collocate all editions and manifestations of a work and all works by or about an author on the screen. The concept of Super Records, as described by Fattahi (1996, 1998), offers catalog users the advantage of searching and retrieving all the instances of a bibliographic family together by presenting a more meaningful display.

\section{d. Flexibility in output/display}

Sorting the search results based on authors' names, titles, subjects, publication dates, relevance ranking, deletion of repetitions, and the like are among the capabilities of many modern bibliographic databases. In addition to saving the time of the user, such capabilities make the display of search results more comprehensible. Many information systems producers develop their products by focusing on such characteristics. Sorting capability is now part of customization and user friendliness of modern IR systems.

Another advantage of electronic records is the possibility of varying the data display at the stage of output. This is because of the structure of the electronic record, which contains fields and sub-fields, permitting outputs to be manipulated according to the needs of users. In other words, there is a kind of flexibility in modern information systems that enables users obtain records from other systems and display them as desired without any extra expense. The purpose is to make information more comprehensible to the user (Yee, 1998).

\section{Management of Information}

A function of information management is to add maximum value to information stored in information system. All the functions named to this point are, in fact, functions of good management, however, here we specifically focus on report generating for managerial and housekeeping purposes.

\section{a. Capability of report production and analysis in information systems.}

Report generating is one of the requirements of almost all management system.

Information systems are no exception. Development of more sophisticated applications permits the generation of a wide range of managerial reports for almost every function of the system. In fact, a system manger is able to added maximum value to the data stored in the system by producing such reports. Managerial reports may include statistics concerning 
the following:

- records in the database,

- records created in, or added to the database in a specific period of time, by different

individuals,

- records generated originally (e.g., through original cataloging),

- records modified, updated or deleted,

- records transferred or copied into the system

- records for each individual author, translator, compiler, etc.,

- items borrowed and returned in each period of time, by each borrower,

- overdue items,

- etc.

All types of reports are, in fact, prepared using the same records created originally for the purpose of retrieval. The system manager prepares such reports and analyzes them to understand the general state of affairs or to learn about specific aspects. Decision making, planning and review of existing programs are the aim of report generation. As such, the system lends added value to the information to be used in ways not predicated at the outset. Chemical Abstract Service (CAS) ${ }^{3}$, as one of the most active and heavily used information systems in chemistry, is exemplary for its report generating capability

\section{Conclusion}

Based on what already has been said in this paper, we can conclude that information is a vital product with capacity to provide added value and that as time passes, the strategic importance of information increases. That is because of the characteristics and capacities of information and information systems. In addition, the more an information system is used, the higher becomes its value.

In the matrix below, different functions of information systems and their capabilities are shown. To achieve these capabilities depends on the management of the system in establishing the relevant structure and the plan to implement it. A point worth mentioning is that, based on the matrix most of the functions in the first column fall exclusively within the purview of library and information professionals. Library and information professionals have developed principles and processes for such activities. Functions such as selection, acquisition, description, dissemination and management are among them. Other functions such as storage, integration, search and retrieval, also fall in the realm of library profession.

Matrix 1. Matching information system functions and capabilities producing added value

${ }^{3}$ Chemical Abstract Service (CAS(www.cas.org/infopro/infoprovide.html)) provides the following routine reports: Journal reports/ patent report/Journal and patent report/substance report with properties/substance table/substance table with properties 


\begin{tabular}{|c|c|c|c|c|c|c|c|c|c|}
\hline Capabilities & 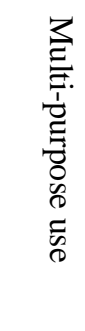 & 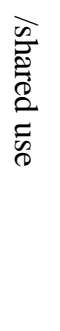 & 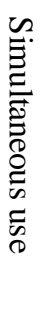 & 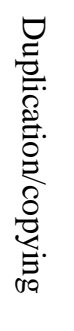 & 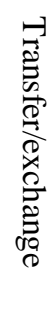 & 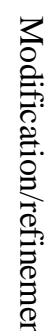 & 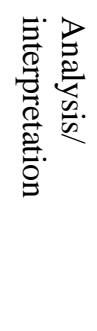 & 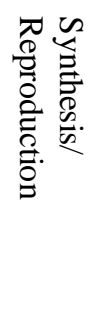 & 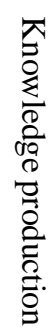 \\
\hline $\begin{array}{l}\text { Selection and } \\
\text { acquisition }\end{array}$ & $\mathrm{x}$ & $\mathrm{x}$ & & & & $\mathrm{x}$ & & & $\mathrm{x}$ \\
\hline $\begin{array}{l}\text { Description and } \\
\text { organization }\end{array}$ & $\mathrm{x}$ & $\mathrm{x}$ & & & & & & $\mathrm{x}$ & $\mathrm{x}$ \\
\hline $\begin{array}{l}\text { Storage and } \\
\text { processing }\end{array}$ & $x$ & $\mathrm{x}$ & & $x$ & $\mathrm{x}$ & & & $\mathrm{x}$ & \\
\hline Integration & $\mathrm{x}$ & $\mathrm{x}$ & $\mathrm{x}$ & & $\mathrm{x}$ & & & & \\
\hline $\begin{array}{l}\text { Search and } \\
\text { retrieval }\end{array}$ & $\mathrm{x}$ & $\mathrm{x}$ & $\mathrm{x}$ & & & $\mathrm{x}$ & & $\mathrm{x}$ & \\
\hline Dissemination & $\mathrm{x}$ & $\mathrm{x}$ & $\mathrm{x}$ & $\mathrm{x}$ & & & $\mathrm{x}$ & $\mathrm{x}$ & $\mathrm{x}$ \\
\hline $\begin{array}{l}\text { Management/ } \\
\text { Housekeeping }\end{array}$ & $\mathrm{x}$ & $\mathrm{x}$ & $\mathrm{x}$ & $\mathrm{x}$ & $\mathrm{x}$ & $\mathrm{x}$ & $\mathrm{x}$ & $\mathrm{x}$ & $x$ \\
\hline
\end{tabular}

Under existing conditions, computer science and networking professions have been able, through automation and optimizing methods of storage and retrieval, to enter this realm and take control of it. However, in instances where the knowledge and the experience of librarians and information workers have supported the work of computer scientists in developing systems, a higher added value of information has become possible. When speed, accuracy, and relevance are essential to information systems, utilizing the expertise of computer scientists is unavoidable. Therefore, librarians and information scientists need to explore ways to interact more closely with computer experts. They should need to try to identify ways and methods of adding value to information systems. The report of a task force of the Special Libraries Association (quoted in Matarazzo, et al., 1987) stresses that information professionals must be prepared to prove the value of their services through one or more of the following approaches: 1) measuring time saved;2) determining actual monetary savings or gains; or 3) providing qualitative, anecdotal evidence of value.

Another important point LIS professionals can rely on, is that as long as information is produced and consumed as a strategic commodity, and as long as access to relevant information requires selection, description, storage, organization, and dissemination, their professional services will continue to be indispensable to society. This, as discussed earlier, depends furthermore on their ability to identify strategies for adding value to information 
through professional education, research, and practice. Current needs, the pressures of time, and scarcity of resources require us to enhance our knowledge about the ways in which we can create more value for information and information systems. This, in turn, requires that education for library and information science be continually revised in this direction. If this proves to be the case, we will continue to perform as the leading profession with regard the management of information and knowledge in society.

\section{References:}

Bothma, T.J.D. (1996), "Added Value in Electronic Publications", In. Proceedings of $20^{\text {th }}$ International Online Meeting; proceedings, London 3-5 Dec 1996 / edited by David I.Raitt and Ben Jeapes. Oxford : Learned Information Europe, pp. 459-470.

China Shanghai official website: (www.Shanghai.Gov.cn/gb/shanghai/english/economy/)

Fattahi, R. (1996), "Super Records: An approach towards the description of works appearing in various manifestations", Library review, Vol. 45 No. 4, pp. 19-29

Fattahi, R. (1998), "AACR2 and Catalogue production technology", Proceedings of the International Conference on the principles and Future Development of AACR, Toronto, 23-25 October 1997. Edited by Jean Weihs. Chicago: ALA, Canadian Library Association, Library Association, pp. 17-43.

Fattahi, R. and Parirokh, M. (2002), "Restructuring the bibliographic record for better management, organization and representation of knowledge", Challenges in knowledge representation and organization for the $21^{\text {st }}$ Century: Integration of knowledge across Boundaries; Proceedings of the Seventh International ISKO Conference, 10-13 July 2002, Granada, Spain. Edited by Maria J. Lopez-Huertas and Francisco J. MunozFernandez. Granada: Ergon Verlag, pp.107-112.

Griffiths, J. and King, D. (1993), Special Libraries: Increasing the Information Edge. Washington, DC: Special Libraries Association.

Hayes, R. (1997), "Economics of information", International encyclopedia of information and library science/ edited by John Feather and Paul Sturges. London; New York: Routledge, pp.116-129.

Keyes, A. (1995), "The Value of the Special Library: Review and Analysis", Special Libraries, Vol. 86 No. 3, pp. 172-187.

Koenig, M. (1992), “The Importance of Information Services for Productivity: Underrecognized and Under-invested", Special Libraries, Vol. 83, No. 4, 199-210.

McGee, J. and Prusak, L. (1993), Managing Information Strategically. The Ernst \& Young Information Management Series. New York: John Wiley \& Sons, Inc.

Macgregor, G. (2003), "Collection-level descriptions: metadata of the future?", Library Review, Vol. 52 No. 6, pp. 247-250.

Maguire, C. (1990) An Australian perspective on the value of information, in National Think Tank on Library Statistics, edited by F. Exon and K. Smith. Publisher: Perth.

Matarazzo, J., et al. (1987), The President's Task Force on the Value of the Information Professional: Final Report. Washington, DC: Special Libraries Association.

Matarazzo, J. and Prusak, J. (1990), "Valuing Corporate Libraries: A Senior Management Survey", Special Libraries, Vol. 81 No. 2, pp. 102-110.

The New Palgrave dictionary of economics and law/ edited by Peter Newman.- London: Macmillan Reference, 1998.

Online Computer Library Center. (1998), OCLC Annual Report. Dublin (Oh.): Online 
Computer Library Center.

Saracevic, T. and Kantor, P. (1997), "Studying the value of library and information services.

II. Methodology and Taxonomy", Journal of the American Society for Information Science, Vol. 48 No. 6, 543-563.

Taylor, R. S. (1986), Value-added processes in information systems. Norwood, NJ: Ables.

Volpe National Transportation Systems Center. (1998), "Value of information and information services", available at: www.fhwa.dot.gov/reports/viiscov.htm (accessed: 12 February 2005).

Woldring, E. (2001). "Strategies to measure the value of special libraries", Rivers of knowledge: 9th Specials, Health and Law Libraries Conference, Canberra, 26-29 August 2001, available at:

http://conferences.alia.org.au/shllc2001/papers/woldring.html (accessed: 1 August 2005)

Yee, M. and Layne, S. (1998), Improving Online Public Access Catalogs. Chicago (Illinois): American Library Association. 